\title{
Informing in the Flat, Rough World: Balancing Globalization Gone Awry
}

\author{
Bob Travica \\ University of Manitoba, Winnipeg, Manitoba, Canada \\ btravica@cc.umanitoba.ca
}

\begin{abstract}
The purpose of this article is to explore effects of ongoing economic globalization by focusing on the organizational and informing aspects of the key globalization stakeholder - the transnational corporation. This is an organization with superior capabilities rooted in digital information and information technology. It is argued that the transpired globalization driven by transnational corporations (among other actors) has imbalanced the world system, which is indicated in significant economic and other differences around the world. Since actions of a transnational corporation impact inevitably and often adversely various stakeholders in the world system, informing within this corporation is not merely a technical task but rather globalization-shaping action with various ramifications. Both the transnational corporation and the environmental consequences of informing associated with it are important topics that could expand the scope of informing science research.
\end{abstract}

Keywords: informing, globalization, transnational organization, world system

\section{Introduction}

The following discussion will explore ongoing economic globalization from the perspective of the dominant organizational form - the transnational corporation (TNC) (Bartlett \& Ghoshal, 1989). The backdrop to analysis is the world that has dramatically changed in the past 30 years. Economic systems across national states have demonstrated a trend of isomorphism. Principles of market-driven economy in a capitalist mould have become nearly universal, suppressing alternatives in the process. Political systems also show a tendency to look alike within the regional and/or global context. In the cultural domain, artefacts from different countries have become more visible globally, engendering advent of "world music," international cuisine, shared consumption preferences, and life-styles. These trends toward global isomorphism are studied under the rubric of "globalization," referring to cross-disciplinary research that ranges from investigative journalism to specialized areas of economics, political science, political economy, cultural studies, and information/information systems. Globalization can be certainly traced further back

Material published as part of this publication, either on-line or in print, is copyrighted by the Informing Science Institute. Permission to make digital or paper copy of part or all of these works for personal or classroom use is granted without fee provided that the copies are not made or distributed for profit or commercial advantage AND that copies 1) bear this notice in full and 2) give the full citation on the first page. It is permissible to abstract these works so long as credit is given. To copy in all other cases or to republish or to post on a server or to redistribute to lists requires specific permission and payment of a fee. Contact 0HPublisher@InformingScience.org to request redistribution permission. in the past and tied to intercontinental voyage, trade, and conquest. Still, the pace and magnitude of changes have been unprecedented in the last 30 years. Following this premise, the present discussion focuses only on this period. In addition, just the economic domain is under analysis, while other domains will be addressed only when they are directly related to the economy. 
Researchers of globalization are not just from academia but also from other occupations, including journalism, politics, and economics. The researchers agree on the basic concept of globalization: barriers to international expanding of economic, political, and cultural structures, actions and products have been diminishing and give rise to global phenomena (Castells, 1996; Friedman, 2007; Fukuyama, 1992; Jones, 2003; Klein, 2008; Levitt, 1983; Stiglitz, 2002, 2006). Many researchers also agree that information, information technology or information and communication technology (either referred to by "IT"), information systems, and telecommunications networks are the forces behind globalization (Bartlett \& Ghoshal, 1989; Castells, 1996; Jones, 2003; Levitt, 1983). Financial markets run on global computer networks; firms source, produce, and sell around the world owing to interconnected information systems; political processes are affected by economically-relevant information that is promptly disseminated by the Internet and other channels; and TV networks, film, and the Internet communicate globally cultural artefacts, driven by commercial interest or otherwise. However, researchers disagree in valuing results and direction of globalization, its drivers, and the character of information and IT.

In valuing globalization results, two confronted camps have morphed. There is a camp of enthusiasts, which values the unfolded globalization as the process that brings benefits to all countries regardless of their economic and political differences (Friedman, 2007; Levitt, 1983). The opposed camp criticizes globalization results, arguing that globalization disproportionally benefits more powerful countries and represents a new form of their domination (Hiatt, 2007; Klein, 2008; Perkins, 2004). The globalization enthusiasts assume that the globalization process is heading toward a higher level of development of the entire human race, a new renaissance, even to finally achievable parting with an undignified history (Fukuyama, 1992). For the globalization critics, however, globalization leads merely to escalating poverty, pollution, famine and other old problems for the majority of people, if not to a new barbarism (Chossudovsky, 2003; Klein, 2008). Researchers also differ in identifications of main drivers of globalization. For some, the chief driver is international or supra-national organizations, such as the International Monetary Fund, World Bank, and World Trade Organization (Chossudovsky, 2003; Klein, 2008; Stiglitz, 2003). Other researchers point to a new form of corporation as the chief globalization driver (Bartlett \& Ghoshal, 1989; Jones, 1998, 2000; Leong \& Tang, 1993). The third camp is populated mainly by globalization enthusiasts who postulate that free markets occupy the driver's role. Finally, characterizations of information and IT depend on an assumed direction of globalization, thus painting these as the forces of either progress or regress.

The thesis argued in this article is that results of globalization are somewhere between the enthusiastic and critical portrayals, or contradictory. In accord with Bartlett and Ghoshal's (1989) stance, it is assumed that the driving force of globalization is TNC. Is it further assumed that TNC is powered by information and information technology (IT). In contrast to one-dimensional characterizations of globalization's final outcomes and of information/IT, an uncertainty position will be advocated. In a nutshell, juxtaposed to TNC are affected globalization stakeholders that resist, compete, and cooperate with TNC. The ensuing dynamics is not likely to engender a predestined world system but rather stochastic one. It will be further argued that the state of the world system calls for rectifying globalization for the sake of advancing the world system into a state of balance. Moreover, the discussion will link the theme of globalization with the perspective of informing (Cohen, 1999, 2009; Gill \& Cohen, 2009). This will lead to questioning environmental/global consequences of organizational informing.

The epistemology behind the following analysis combines concepts from systems sciences complex systems theory, world-systems theory, and social cybernetics. The second part of the framework refers to theorizing on information and information systems from the perspectives of informing science (Cohen, 1999, 2009; Gill \& Cohen, 2009) and the information view of organization (Travica, 2005a). The analytical method deployed is stakeholder analysis. In the particular 
form applied here, stakeholder analysis focuses on characteristics and action of the main stakeholder, TNC, in conjunction with affected stakeholders.

\section{The World is Flat: Globalization Enthusiasts}

Every morning in Africa, a gazelle wakes up. It knows it must run faster than the fastest lion or it will be killed. Every morning a lion wakes up. It knows it must outrun the slowest gazelle or it will starve to death. It doesn't matter whether you are a lion or a gazelle. When the sun comes up, you better start running. (Friedman, 2007, p. 137)

Friedman's metaphor signifies well the proponents of the transpired globalization process who maintain that the world has become an even playing field. Friedman popularized the phrase "the world is flat," which was the title of his investigative journalism-based book (first published in 2005). His argument suggests that every country today is in the same game. Whether a country is strong (economically, politically, and culturally) or not so strong, it is in the game based on rules of speed, competition, and survival of the fittest. The playing field has become even through globalization of principles of free market economy. While the role of the pray has always been about the same in history, the new aspect that the argument of world's flattening brings up refers to the predator. The predator is in the same game of globalization as the prey, and indeed the former is dependent on the latter.

The current age is supposed to be differentiated from the old ways of bringing the world together through forcefully colonizing other territories. Colonial powers had endeavoured to shape the global trade and competed militarily with one another in order to conquer lands from which they could extract wealth and super profits. In contrast, the flat world of today is portrayed to be the one in which the predator and pray interchange the roles since they, being driven by the same economic principles, are assumed to have the same chances for survival. In his much publicized advocating of the flat world, Friedman (2007) provides many vignettes of countries, regions, and companies that come out as free market winners (became predators) or losers (fell into the prey role) in the globalization game, reserving special praise for economic achievements of China.

This optimistic view of globalization has its academic proponents and indeed precursors. For instance, Levitt (1983) used the phrase "earth is flat" in a paper that could be taken as a manifesto of globalization:

The result is a new commercial reality - the emergence of global markets for standardized consumer products on a previously unimagined scale of magnitude. [...] Corporations geared to this new reality benefit form enormous economies of scale in production, distribution, marketing, and management. [...] Worldwide communications carry everywhere the constant drumbeat of modern possibilities to lighten and enhance work, raise living standards, divert, and entertain. [...] Cosmopolitanism is no longer the monopoly of the intellectual and leisure classes; [...] it breaks down the walls of economic insularity nationalism, and chauvinism. (pp. 183, 192)

\section{The World is Rough: Globalization Critics}

Other researchers of globalization question the argument of the flat world. Appropriately enough, thoughts of another prominent investigative journalist can characterize this camp. Klein (2008) has pointed out that globalization refers to the ideology and a global assault of neo-liberal capitalism. These are associated with a corporatist model of capitalism been based on doctrines of Milton Friedman and the Chicago School of Economics, which exhibits particular features: 
Its main characteristics are huge transfers of public wealth to private hands, often accompanied by exploding debt, an ever-widening chasm between the dazzling rich and the disposable poor, and an aggressive nationalism that justifies bottomless spending on security. For those inside the bubble of extreme wealth created by such an arrangement, there can be no more profitable way to organize a society. But because of the obvious drawbacks for the majority of the population aggressive surveillance (once again, with government and large corporations trading favours and contracts), mass incarceration, shrinking civil liberties and often, though not always, torture. (Klein, 2008, p. 18)

Criticism of globalization comes also from academic economists. The Noble Prize winner for economics and the former World Bank insider, Joseph Stiglitz $(2003,2006)$ criticizes the very core of the dominant globalization paradigm of "market fundamentalism":

I spent almost forty years working on understanding the strengths and limitations of the market economy. My research had not only cast doubt on the validity of general claims about market efficiency but also on some of the fundamental beliefs underlying globalization, such as the notion that free trade is necessarily welfare enhancing. [...] Without appropriate government regulation and intervention markets do not lead to economic efficiency. [...] The pursuit of selfinterest by CEOs, accountants, and investment banks did not lead to economic efficiency, but rather to a bubble accompanied by massive misallocation of investment. And the bubble, when it burst led, as they almost always do, to recession." (Stiglitz, 2006, pp. $x$, xiv)

For much of the world, globalization as it has been managed seems like a pact with the devil. A few people in the country become wealthier, GDP (Gross Domestic Product) statistics, for what they are worth, look better, but ways of life and basic values are threatened. [...] Closer integration into the global economy has brought great volatility and insecurity, and more inequality. (p. 292)

\section{Globalization Twenty Years After: The World is Flat and Rough}

What indeed is the world like after years of being moved by the latest wave of globalization? This wave was triggered in 1989 by several important events. In Poland, a new political party resulting from the trade union movement Solidarnošć won in the first free elections after World War II, indicating a shift of power in European mono-party, socialist political systems; in Germany, the Berlin Wall went down, symbolizing a reduction of barriers between two major economic/political blocks that dominated the world scene for decades; and in China, demonstrations for expanding civic liberties at Tiananmen Square ended in a bloodshed, showing the resolution of the government to maintain the mono-party political system while staying on the course of market-driven economic reforms. Also in 1989, in the United States, the so called Washington Consensus was publicized (cf. Serra \& Stiglitz, 2008), and Francis Fukuyama (1992), academic philosopher then working at the State Department, announced "the end of history." Rather than being merely symbolic, both events revealed a determination of major global lending institutions, corporations, and policy-making groups to make a global push for neo-liberal capitalist reforms (unregulated markets and trade, privatization of public enterprises, a minimal role of the government in economy and social services; also called New World Order, laissez faire capitalism, capitalism with wolf's teeth, savage capitalism, and so on).

Twenty years after, outcomes of the globalization process are portrayed in the contrasting terms discussed above. However, the reality behind sharply contrasted arguments is usually that each 
side is partly right - and partly wrong. It can be argued that there are both up- and down-sides to the unfolded globalization for the stakeholders involved. There is some improvement in macroeconomic parameters of the developing world and in certain developing countries (e.g., some Latin American and east European countries, China, and India). In the period 1989-2007, the annual Gross Domestic Product (GDP) per capita on the average has grown $4.79 \%$ in the developing world as opposed to a slower growth of $2.47 \%$ for the developed world. (Swivel Preview, 2009) The same data, however, show significant gaps between regions - East Asia without Japan (that lowers the figure) recording remarkable $7.53 \%$ of GDP growth, sub-Saharan Africa 3.19\%, Latin America 2.99\%, while the countries of the former Soviet Union taken together have had just $0.26 \%$ average annual growth.

Significant difference exists between countries as well. While China and India have led the growth trend (9.46\% and 6.1\%, respectively) and Costa Rica scored high (4.9\%), Poland, Slovenia and Hungary faired below the developing world's average $(3.61 \%, 3.29 \%$, and $1.89 \%$, respectively). Even with the growth, the nominal GDP/capita in more developed countries is significantly larger than in developing ones (e.g., in 2008, Luxembourg had US\$113.044 GDP/capita, the United States $\$ 47,700$, Japan $\$ 38,457$, Slovenia $\$ 27,149$, Hungary $\$ 15,523$, Poland $\$ 13,846$, Costa Rica $\$ 6,544$, China $\$ 3,259$, and India $\$ 1,017$ (IMF data as cited by Wikipedia, 2009). Note that the selection of countries is motivated by purposes of the further analysis.) and globalization did little to reduce poverty. It remains a significant problem indicated by the fact that a half of world's population lives below \$2/day (Sachs, 2005).

The inclusion of new labour markets doubled the size of global workforce by 2000 (Freeman, 2007). This change enlarged an international pool of skill, talent, and overall production capacity. Ultimately, capital appears the true beneficiary: the capital-labour ratio was nearly halved, since suppliers of new labour to the global market (China, East Europe, and India) brought in little capital (Freeman, 2007). In effect, the supply of work doubled while the supply of capital roughly stayed the same, or the demand for capital roughly doubled. The end result is that competition for jobs skyrocketed in the global labour market, thus depriving labour of bargaining power and making capital the winner. A phenomenon resulting from this tension between capital and labour is production offshoring. Seeking cost reduction and a profit margin increase, capital keeps migrating. From the labour perspective, the USA has feared offshoring to Mexico, then Mexico feared offshoring to China, China to India, Germany to Poland and Hungary, and so on (Paus, 2007). The professional workforce in the information technology sector in the developed world has felt consequences of offshore outsourcing to the developing world.

A novel riche class was formed in transition economies, such as princelings in China, oligarchs in Russia, and piranhas in Chile (Klein, 2008, p. 17). Although variation between regions and countries exists, a significant source of wealth for this new class has been appropriation of public or state property. This class is the primary beneficiary of emerged global flows of modern consumer goods and services, including luxury ones. In contrast, the gap between the rich and the poor has widened globally. For example, just a few percent of adults own more than a half of household wealth globally (Klein, 2008, p. 535, citing a UN report). In China, the economic gap between the rural population of 800 million and city dwellers has doubled over the past 20 years (Klein, 2008, p. 534). Globally, the middle class is shrinking - in the former socialist countries and in the developed countries alike, such as the USA where an impoverished population of temporary employees keeps growing (Sachs, 2005).

Firms with global capabilities benefit immensely from globalization because they have an increased access to global markets of supplies, labour force, and customers and do command global efficiencies of scale (Levitt, 1983) and diverse knowledge (Bartlett \& Ghoshal, 1989). For them the world may look "flat" (Friedman, 2007; Levitt, 1983). Host countries also benefit, particularly from the new jobs, tax income, direct foreign investment in production, and transfer of tech- 
nology and scientific and management knowledge (Stiglitz, 2006). In contrast, however, native business is exposed to difficult competition and it may even perish.

Political systems based on European and American traditions of the parliament and multi-party competition have been implemented in many countries in transition and in developing countries. In principle, this political change should have facilitated the development of competition-based market economy since freely elected political representatives are supposed to promote interests of economic actors - capital (economic enterprisers) and labour. However, the actual involvement of people in policy-making is contrasted by ineffective and corrupted many-party establishments. Money increasingly plays a role in politics. This trend favours richer players. In particular, TNCs and supra-national organizations can have much influence. For instance, to maximize their gains, a $T N C$ may bribe local politicians in order to influence legislation in its favour (e.g., bills that circumvent environmental regulations (Stiglitz, 2006)). Globalization "often seems to replace the old dictatorships of national elites with new dictatorships of international finance" (Stiglitz, 2003, p. 247).

Diverse knowledge is more accessible owing to the Internet and online education. In contrast, economic constraints hinder education, ultimately reducing access to knowledge and education. Education budgets drop globally because foreign lenders that dominate global capital markets control indebted governments and thus public spending (Chossudovsky, 2003; Klein, 2008; Stiglitz, 2003). In the developed countries, governments can have significant internal debts and can be pressed by domestic lenders into "fiscal discipline," which usually means less money for education. As a result, the funds for expanding the physical computer network meet severe limitations, which in part are indicated by a significant digital divide (see more on the Internet penetration below).

The hot Latin American salsa dancing has hit cold Scandinavia, Bollywood movies fill the shelves of video stores in Canada, and the "world music" is played in specialized radio-programs around the globe. In contrast, propelled by powerful media and entertainment industry, Western pop-culture artefacts, like reality TV, Hollywood blockbusters, and music still cross borders more easily than comparable products of art from other parts of the world. The information flows spreading from the world's developed core are insensitive to local cultures and tend to supplant these.

The above picture of globalization results clearly demonstrates stark contrasts. Soon after the latest wave of globalization started, Handy (1995) characterized the process with the term "paradox." He argued that progress came with price of efficiency and failure, and freedoms with less equality and more misery. Instead of expected security that was supposed to follow from the fall of the Berlin Wall, the world became engulfed in confusion, surprises, and hardship. Jones and Fleming (2003) have also associated globalization with simultaneous contradictions of convergence vs. divergence, inclusion vs. exclusion, and centralization vs. decentralization. In particular, whereas a convergence toward shared business practices and cultural contents is ongoing, there is also diverging into local ethnic, religious, and racial entities, as a reaction to the undermining of cultural systems. As for the inclusion/exclusion dynamics, the authors argue that developed countries have become even more included in a shared economic, political, and cultural space, while other countries are increasingly excluded from it: "substantial regions in Latin America, central Asia, and most of Africa (are) simply bypassed as globalization unfolds" (p. 441). And while decentralization at the organizational level happens due to the increasing geographical dispersion and technology-based linking capabilities, centralization may happen within organizational networks dominated by TNCs. 
In summary, globalization results can be viewed from a middle way-perspective that avoids extreme enthusiasm or criticism. Opposed qualities have emerged and co-exist. This perspective has some support in the literature.

\section{Information and IT: Drivers of Transnational Corporation and Globalization}

Why is the phenomenon of globalization important for students of information, IT, and informing? There is an agreement among researchers that IT is a driver behind globalization (Castells, 1996; Freidman, 2007; Levitt, 1983). For example, Levitt (1983) discussed technology as a casual force behind globalization. Similarly, Friedman (2007) saw IT as a "flattener" (a force of globalizing) with regard to group collaboration, widely shared practices of file uploading, and trends of offshoring, and global supply-chaining. Overall, the IT in question is electronic/digital, coming in the form of broadband, multimedia networks and information systems that can be built quickly out of components and set up in the global environment.

\section{Transnational Corporation}

Digital information management and IT enabling it are situated in organizations that drive globalization (Bartlett \& Ghoshal, 1989; Jones, 2003; Stiglitz, 2006). Further analysis will show that TNC is linked to the contrasting effects outlined above. One should note that a distinction between TNC and other concepts with a longer tenure, such as multi-national corporation (MNC), are not clearly spelled out in the literature. Bartlett and Ghoshal (1989) first proposed a concept of transnational organization to refer to an organization with superior capabilities of doing business globally. The transnational organization was supposed to be better suited for the emerging global arena than the models that dominated international business through the $20^{\text {th }}$ century - the multinational, global, and international organization. Structurally, the multinational organization is decentralized (e.g., Procter \& Gamble, ITT), the global organization is centralized (e.g., Matsushita, NEC), and the international organization takes a balanced approach to centralization and decentralization (e.g., Philips, Ericsson). Each of these models has a staple capability: the multinational firm is responsive to local market needs; the global firm exhibits efficiency while treating the world as a single market; and the international firm excels in knowledge creation or a learning capability. As for this last capability, a multinational organization develops knowledge in a distributed fashion and keeps it within the dispersed units, a global organization develops knowledge in the center and keeps it in there, and an international organization relies on centrally developed knowledge and adapts it to local market needs. The authors posited that the transnational organization combines the capabilities these three forms and suggested that convergence toward the international form was becoming a trend.

The literature provides other interesting aspects of TNC. For example, a number of authors have agreed that TNC exhibit a statelessness aspect related to the organization's high spatial dispersion and mobility. Building on these ideas, Leong and Tang (1993) identified TNC with a corporate identity consisting of a network of systems and activities in different parts of the world, capable of deriving value from whichever location provided it at the lowest cost. Important notions here are the organizational mobility caused by a continuous search for cost efficiency. Another aspect of TNC important for this discussion is an ability to extract rents from states, workers, and other stakeholders due to increasing bargaining power TNC has over these groups (Jones, 2000). An aspect of geographical spread should be added to the conceptualization of TNC. The UNCTAD 100 list deploys three ratios that can be used for assessing the extent to which an organizational is transnational - foreign to domestic assets, foreign to domestic employees, and foreign to domestic sales. Apparently, the rations indicated the geographical spread of TNC's production and 
sales. A dimension of distributing sourcing operations should be added to complete this compound measure.

Based on the discussion above, for the purposes of this study a TNC is defined as an organization with the capabilities of global efficiency, local market responsiveness, distributed learning and cross-unit knowledge sharing, and increased bargaining power and mobility, which sources, produces, and sells in the global context. In other words, these are distinct globalizing capabilities of TNC. Figure 1 depicts this form of organization. More traditional forms of organizing for international business tend to evolve toward TNC. Transnational capabilities are a matter of scale. For example, Nike is likely to be a TNC to a larger extent since it globally sources materials and parts, runs production in different countries, and sells around the world. Equivalents in the financial sector would be large financial institutions, such as J.P. Morgan, Bank of America, Deutche Bank, and HSBC. IBM would be an example in the IT sector. In contrast, Walmart would have relatively smaller transnational selling capabilities as it operates in just about a dozen countries, while its sourcing capabilities are more global and bargaining power is significant (often a subject of criticism from the labour perspective). An equivalent in the financial sector would be a Canadian bank that borrows money and lends it just within the American continent. Large software vendors in the developed world (Oracle, Microsoft, Siemens, SAP) develop transnational capabilities as they seek to outsource software development to foreign labour markets that provide technical expertise at lower than domestic costs of labour. TNC can be found in the high-tech sector, financial industry, manufacturing, energy and water, pharmaceuticals, telecommunications, wholesale, retail, and other industries.

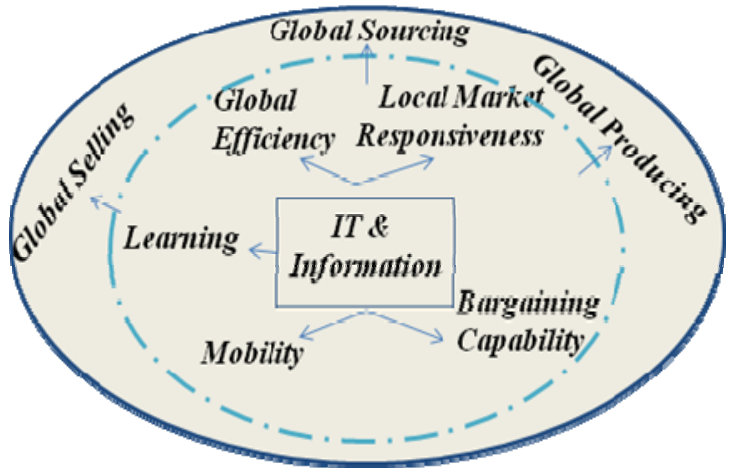

Figure 1. Transnational Corporation

\section{Support of IT and Information to TNC's Capabilities}

Feeding the TNC key capabilities, IT and digital information management lie at the nexus of this organization. Global efficiency of operations draws on distributed enterprise systems that enable tracking operations, reporting, and decision making in a distributed fashion. These systems enable just-in-time inventory management that can extract significant time and money savings from supply chains. A well-known example is Toyota's system that connects the customer with dealerships, Toyota's materials planning and inventory systems, and supply management systems.

The sophisticated IT infrastructure of TNC further allows for close support to flexible local operations, while the data for strategic decision making can still be integrated in data warehouses that pool data from different locations. These present flexible information structures (Travica, 2005a) that facilitate a delicate balance between decentralization and centralization in decision making needed in TNC (Bartlett \& Ghoshal, 1989; Egelhoff, 2005). In turn, this balance paves way to responsiveness to needs of nation-state markets in which TNC operates. Intricate management processes and techniques, helped by systems for communication and decision support, may be deployed to ensure involvement of spatially dispersed and hierarchically differentiated 
management in decision making processes. For example, Kim and Mauborgne (2005) have found that the fairness of decision making procedures ("procedural justice") help make management involved in decision processes and committed to realization of the resulting decisions. In other words, TNC is likely to host a specific infoculture (Travica, 2005a) that complements its centralized/decentralized structure, and both these characteristics enhance TNC's responsiveness.

TNC exhibits a learning capability that is superior to all previous forms of organizing for international business. Technical expertise developed in one corner of the world is spread through the network of subsidiaries. Bartlett and Ghoshal (1989) illustrate how Sweden's Ericsson uses this practice that is superior to keeping new knowledge where it is stored, which is typical for a mutlinational corporation. An example of the latter is ITT, an American company that failed to make a successful transition in the international telecommunications markets due to the way it managed its engineering knowledge. While a multinational's headquarters can enforce certain standards and actively drive knowledge dissemination, TNC benefits from a structural flatness and lateral information processing (Egelhoff, 2005; Galbraith, 1973). Interconnected and integrated information systems for managing documents that index and codify knowledge play a pivotal role in these lateral links among TNC units. From the perspective of infopower (Travica, 2005a), it can be hypothesized that TNC is likely to nurture knowledge-based power that strengthens its learning capability.

TNC's bargaining power is disproportionate to many economic and political players. Stiglitz (2006) provides numerous examples. In Peru, a mining company threatened to move elsewhere if environmental regulations concerning health of children living by mines were inaugurated. The government of Papua New Guinea passed a law that banned using international mining companies outside of the country, fearing that such a law would discourage foreign investments. When an Australian mining company exhausted the mine after polluting significantly two rivers, the company simply walked away. Microsoft left South Korea when it estimated that local legislation was not in its favour. Bargaining power of TNC is positively related to its mobility. This relationship is salient in information-intensive industries. Provided a necessary minimum of electrical and telecommunications infrastructure is in place, banks and other financial organizations can easily start and end business in foreign countries. This is possible because money today takes primarily electronic format, financial markets reside on computer networks, and clients have a digital capability. Consequently, a financial TNC can be operationally present in a foreign country without having much of physical presence in staff and facilities. Leaving a market is also easy, and this has been practiced during the last wave of globalization. Instances of capital migration coincide with almost every remarkable financial crisis in developing countries during the 1990s (e.g., Brazil, Argentina, Russia, Korea, and Indonesia; see Chossudovsky, 2003).

The software industry also exhibits a high degree of mobility. The global software market is dominated by large American, West European, and Japanese firms that emerged through mergers and industry consolidation processes. Striving for global efficiency and profit objectives, these firms tend to outsource software development to places that host expertise that is available for lower pay rates than those in home countries (e.g., in India and east Europe). As IBM's CEO has recently proposed through his concept of globally integrated enterprise, the global integration of operations is forcing companies to choose where they want the work to be performed and by whom - in-house or by an outside partner (Palmisano, 2006). Only recently, competitors from developing countries started to emerge (for example, India).

It can be said that TNC resides in a cyberspace - a space viewed by digital information, information systems, and computer networks. Physically, this space extends wherever communication media reach, including the air (which in itself is a communication medium). Spatially dispersed units are linked via computer network links to the extent that these are indistinguishable from organizational structure (e.g., organizational processes and lines of reporting). Potentially, all the 
work that rests on digital information can be geographically dispersed and may be subject to outsourcing. The cyberspace is also the venue for transacting with customers, suppliers, and business partners. From the inter-organizational perspective, these global electronic organizational networks give rise to new organizational design called virtual organization (Mowshowitz, 1994; Travica, 2005b, 2008). Virtual organization refers to multiple organizations that come together for accomplishing a shared purpose and they act as if they are one organization. The VO rests in the cyberspace, has a changing network membership, and a capability to differentiate its products from competitors (e.g., via mass customization or by building custom products) (Travica, 2005b, 2008). Inter-operability in a virtual organization is achieved primarily through a limited synchronizing in the domain of on infoculture, such as agreeing on shared information practices. Supply chain linking provides the basis for one kind of virtual organization, and examples are Dell Computer and Nike. The virtual character expands capabilities of TNC's global sourcing, producing, and selling as well as its learning, efficiency, and responsiveness. In addition, the virtual character makes TNC's operations even more mobile.

\section{Impacts of TNC on Countries}

Each of TNC's capabilities makes an impact on the global environment. Local business is no match to TNC in terms of knowledge and productivity capabilities. Levitt (1983) rang the toll bell for local business and all organizations focused on local rather global markets. He ascertained that the global corporation using a global economies of scale can "decimate competitors that still live in the disabling gap of old assumptions about how the world works" (p. 183). Stiglitz's (2006) work on inherently imperfect knowledge characterizing market economy and thereby leading to imperfect markets implies that weaker players rather than TNCs are at the receiving end of this asymmetry. In practical terms, when a software giant moves into a country's market, a local software vendor can choose only between joining the giant's eco-system and perishing. Deprived of knowledge of the giant's technological strategies, the local vendor risks making incompatible technology that cannot attract the customer.

Local governments and political establishments, as discussed above, are often compelled to adjust laws to the interests of TNCs. Not only that TNC-dependent stakes are in question (jobs, tax income, foreign direct investment), but TNCs often command larger economic power than governments. For example, in 2004 the revenues of General Motors were bigger than the gross domestic product of 148 countries, while in 2005 Walmart's revenues exceeded the amount of the combined GDP of sub-Saharan Africa (Stiglitz, 2006, p. 187-188). Financial TNCs also possess enormous financial and bargaining power. They can have certain control even over national banks (government institutions) - both in the developing and developed world (Chossudovsky, 2003). Financial transnationals can also influence countries via TNCs that borrow money from them. Moreover, TNCs can increase their impact via cooperation that indeed violates principles of market economy. Cartels can be created in order to beat the competition and to fix prices at a profitable level for the members. If they target staple products of weaker national economies, then entire countries suffer (Stiglitz, 2006, pp. 199-203).

Political impacts of TNC's emanate from their economic power. These impacts can also be directly induced by informing processes in the area of public relations, with the purpose of manipulating public opinion and the political system in a host country (Stiglitz, 2006). TNCs in the sector of mass communication (e.g., CNN) also have a significant political influence in the international context. Driven by powerful commercial interest, the entrainment and popular culture sector (TV networks, film studios, and music labels) in the developed countries impacts on other cultures. An Anglophone impact is apparent, but cognitive influences reach much deeper as the mainstream values and ideologies of the informer are communicated. Convergence between the 
foreign and local artefacts results in many areas, such as in life styles, consumerism of the urban youth, and even the modes of crime and corruption (Nayyar, 2008).

Overall, TNCs in many sectors make impacts on country-level stakeholders - local business, labour, government, political parties, mass information media, and carriers of popular culture, and the population residing in the physical environment of TNC's operations. The impacts are often adverse to interests or tradition of the affected stakeholders.

\section{Impacts of TNC on the World System}

The extension of stakeholder analysis in preceding sections identified TNC as a key player in globalization processes affecting various stakeholders in the context of country (nation-state). But TNC reaches to a higher level of the entire world understood as a system. The term "world system" used in this analysis draws on some ideas from world-systems theory (Prebisch, 1950; Wallerstein, 1974). In particular, it is assumed that the world is a whole consisted of a developed core and of a less developed periphery, and that interaction and exchanges between these two parts are shaped by their asymmetrical power positions. However, the concept of world system does not assume the teleology of the contentious core-periphery relationship, which is part of world-systems theory.

As rational economic actors, TNCs naturally strive to instil principles of deregulated trade and markets, which give the strongest players the best chances of quickly achieving profit gains. TNCs fit the playmaker role in Castells's $(1996,2000)$ framework on "informational capitalism." This framework is aiming at understanding the developments associated with global spreading of similar economic practices that are empowered by computer-based information systems and networks. In explaining informational capitalism, Castells (1996) states: "It is informational because the productivity and competitiveness of units or agents in this economy [...] fundamentally depend upon their capacity to generate, process, and apply efficiently knowledge-based information" (p. 66). In further elaboration, Castells (2000) posits that IT bends concepts of time since business runs non-stop, as if the present is the only time dimension. Geographical and nation-state boundaries are transcended. Inclusion in global electronic networks (supply or value chains) is a condition for becoming part of the global economy. Therefore, technological capability is a necessary condition for sustainable development. A new concept of productivity characterizes informational capitalism: "a global network of interaction" determines bounds of productivity (Castells, 1996, p. 66). While questioning tenability of the notion that TNC is an "institutionally bounded reality" (1996, p. 192), Castells focuses on inter-organizational global networks as the key player in globalization. It can be argued, however, that the concept of organizational networking is embedded both in the concept of TNC and virtual organization discussed above. Finally, informational capitalism imposes cultural and social changes: "The spirit of informationalism' is the culture of 'creative destruction' accelerated to the speed of the optoelectronic circuits that process its signals" (Castells, 1996, p. 199).

Since informational capitalism imposes itself as the model of the world system, acceptance of the former is the necessary condition for the inclusion in the latter. The stakeholders exposed to this pressure are numerous, starting at the regional and country levels. Countries in east Europe illustrate well this difficult transition process exhibiting both successes and failures. Within countries, large social groups constitute stakeholders at the mezzo level. They have had formed upon three bases - capital (a small novel riche class commanding significant wealth with suspicious origins, and small entrepreneurs), labour (most of it released from destroyed publicly owned enterprises), and marginalized population (unemployable and severely impoverished). For labour and small entrepreneurs, access to computers, the Internet, and knowledge of English present necessary conditions for access to better jobs and social mobility. At the micro level, stakeholders are economic organizations that have to become part of organizational networks and virtual organiza- 
tions created by TNCs. In addition to technological capability, the peripheral organizations also need to master professional, organizing, and management skills that are attractive to TNCs, as suggested in the conceptualization of TNC above.

Jones's (1998) dichotomy of "techno-economy" versus "grunge economy" can help in shedding more light on stakeholders at the periphery. The former economy is carried by sectors that are intensive in technology, knowledge, and capital, deploy multi-skilled labour force and advanced management techniques, and generate high value-added and profitability. The techno-economy can be found in several industries, including telecommunications, computer software and hardware, consumer electronics, financial services, weapons research and production, and pharmaceuticals. These provide a lucrative employment, where mental work is the standard. From the organizational perspective, the staple trait of techno-economy resembles Handy's (1989) Triple Iorganization that promotes information, intelligence, and ideas into core assets. In contrast, the grunge economy exhibits a simpler, repetitive, lower paid, and temporary work. It is usually in the role of subcontractor to the techno-economy. Another point of connection between incumbents of these two economies can be can be within the same organizational boundaries. Another Handy's (1989) design called shamrock can help understand this possibility.

In a shamrock organization, there is a professional core that makes a permanent unit ("leaf"), which hires temporary workers (the second organizational leaf). These workers fill a need for extra work when demand surges in the domain of low-skilled operations (component assembly, data management, payroll processing, etc.). Thus, the techno and grunge economies meet in the same organization. Moreover, the grunge economy also contains segments of the grey economy - unskilled, redundant, immigrant, and sweatshop workers. It is likely that most of organizations and social groups at the periphery of world system are to be included in global informational capitalism in the form of grunge economy. It is important to note that TNC represents a less centralized organizational form, while it centralizes decision making over the elements of grunge economy that TNC comes in touch with. This proposition conforms to the globalization contradiction advanced by Jones and Fleming (2003).

Access to the Internet in part determines technological capability of actors in the world system. In spite of leaps developing countries have made into the Internet age, there are still significant digital divides. Figure 2 depicts dramatic differences between continents with respect to the ratio of the number of people with Internet access and the total population. Huge differences exist within continents as well. For example, the range of Internet penetration in European countries is between 10\%-80\% (Internet World Stats, 2009).

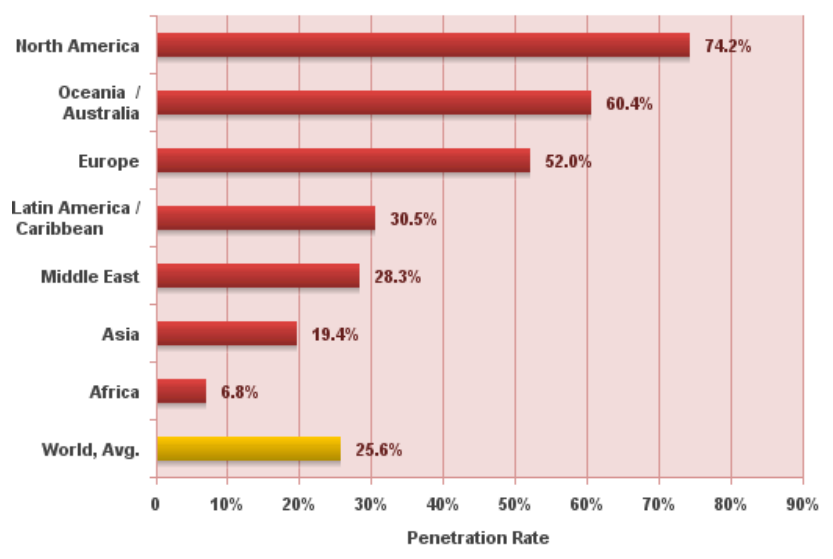

Figure 2. Internet penetration rates around the world (Source: Internet World Stats, 2009) 
In summary, a TNC is an organization with the capabilities of global efficiency, local market responsiveness, distributed learning and cross-unit knowledge sharing, and increased bargaining power and mobility; TNC sources, produces, and sells in the global context. Information and IT play a key role in TNC. Impacts of TNC on the world system can be understood in terms of a dichotomy between the techno-economy and grunge-economy as well as in terms of informational capitalism that splits the world system into a core and a periphery.

\section{Correcting Imbalanced Globalization}

The analysis above revealed that globalization in the past 30 years has been imbalanced. IT and digital information are the forces behind this imbalanced globalization. It appears that the time of paradoxes and of the unreasonable (Handy, 1989, 1995) that challenges conventional wisdom has extended to date. Although all the players experience both benefits and costs, the distribution of these is imbalanced in favour of the core. But if the world is paradoxical and unreasonable, it does not mean that dealing with such world should also be unreasonable. The position advocated in this article is not to oppose globalization, in spite of its significant pitfalls. As Indian poet Rabindranath Tagore sensed, a noble goal is to create a world that is not broken up into fragments by narrow domestic walls and where a clear stream of reason has not lost its way into a desert of dead habit. Cognizing, acting, and enacting change do constitute a reasonable position in the unreasonable world. This is so because globalization has no predetermined end. Rather, outcomes of globalization are yet to be shaped through action of different players.

Balancing the globalization process and deploying IT and information toward this end should rectify the crying gaps this process has created in the world system. The very preservation of the world system may be at stake. Another reason for balancing globalization is motivated by the law of requisite variety (Ashby, 1958). According to this principle, a system is stable if its control mechanism has a number of states equal to or greater than the number of states in the system the mechanism controls. In other words, the model of global economy has to meet the variety of the world the model attempts to control. The following discussion will show that the mainstream model of globalization does not satisfy this law.

In spite of all the isomorphism globalization has delivered so far, there is evidence that local characteristics, needs, and capabilities have already been imparted on globalization. For example, Lal (2007) studied small and medium enterprises (SMEs) in Costa Rica's apparel and food/beverage industry, which had contributed on the average $30 \%$ to the country's exports in the period 1990-97. He found that IT contributed to productivity in these firms in correlation with management and IT-related knowledge of general managers/owners and their international orientation. On the other hand, access to the Internet, which was crucial for international orientation, was being provided by a government-owned telecom. These managers did not consider this fact to be a constraint to business. Even though Costa Rica has followed market orientation for decades and has had the most stable economic and political system in Latin America, this country has cautiously walked the path of privatization and deregulation (Travica, 2002). The result is a variant of globalization model that could be interesting for other small countries.

On the other side of the world, India as a large globalization player, with record rates of GDP growth, has also been globalizing in its own way. Roy (2005) demonstrated how the free market model was modified through involvement of non-prescribed stakeholders, such as the government, trade unions, and support networks. These helped in buffering the uneven development of new economy triggered by offshoring of IT services from developed countries to India. While the IT sector in Bangalore was innovative and became self-sustainable and internationally competitive, its counterpart in Mumbai was more dependent on foreign investment. Thus, the latter needed domestic institutional support and indeed benefited from help provided by the above cited stakeholders. If it were directly exposed to fluctuations in offshoring demand, the Mumbai IT 
industry would have perished. Rejecting the prescript of fully deregulated financial markets, India (much like China) has restricted short-term capitals flows in order to protect its economy from destabilizing and speculative movements of foreign investment, which in the late 1990s caused a deep crisis in other successful economies of the Far East (Stiglitz, 2006).

Historical characteristics of particular countries have also influenced differences in globalization paths. Piatkowski (2006) analyzed the relationship between IT investment and productivity in Czech Republic, Hungary, Poland, and Slovenia in the period 1995-2003, the countries in Central/East Europe that recently joined the European Union. He found that productivity grew faster in these countries than in the old European Union, and that it correlated with investments in IT. The author concluded that the direct foreign investment, European Union contributions, overall quality of economic and institutional environment, innovation, and human capital were among the factors that differentiated these countries among themselves and from some other countries in the region (e.g., Russia). However, it could be argued that each of these countries has had different historical conditions and underwent a different globalization path, although they are often conveniently lumped into a category of "former communist countries." For example, system changes in Poland were initiated by a trade union movement that pursued essentially non-capitalist reforms when it beat in free elections the ruling communist party in 1989. Although the new government swallowed the sour pill of economic and social reforms pushed by IMF and the World Bank, the privatization of large state-owned enterprises in Poland have been implemented just to a limited extent. Some of these still exist and compete in the market (Klein, 2008). Therefore, Poland's specific path to globalization has roots partly in the historical episode (actors, events, outcomes) that marked the country's turn toward globalization.

Particular historical and cultural characteristics influenced Slovenia's integration in global economy as well. Slovenia came out of a country called Yugoslavia in which market reforms had started three decades before those in Poland. Preceding the fall of the Berlin Wall, economic reforms in Slovenia were gradual and supported by the ruling "communist" party that primarily pursued a pragmatic economic agenda (Kovacic \& Travica, 1992). In Slovenia, market reforms found a more fertile ground than in other parts of Yugoslavia due to middle-Europe's traditions Slovenia was exposed to through centuries (Kovacic \& Travica, 1992). In addition, Slovenia had convenient access to advanced IT since the regional headquarters of IBM and a training center were stationed in it. With disintegration of Yugoslavia in 1991, Slovenia continued the transformation of its economy, while pursuing a more cautious approach to privatization of large public enterprises. For instance, it implemented a distinct hybrid model of privatization (Simoneti et al., 2001), thus avoiding a massive sell-out of economic assets to foreign interest, which happened in Hungary and in Russia under the Yeltsin government. These particular historical conditions suggest again that globalization takes much more than a country's decision to go by deregulated markets and free trade.

Some other countries have imparted their characteristics on globalization as well. By focusing on India from the perspective of human capital as a globalization factor, one can identify a number of stakeholders that impart a distinctive imprint on the country's path to globalization. These include long-lived institutions of technical education, the government's promoting of science and technology programs, entrepreneurial software industry that turned the Y2K problem into an opportunity for expanding its share in the international IT industry, the graduate with English language proficiency, and the improviser that circumvents weaknesses in the country's power grid and telecommunications networks to link up economy to the Internet (Roy, 2005; Suri, 2007).

These cases of globalization confirm the proposition on simultaneous convergence and divergence trends in globalization (Jones \& Fleming, 2003). The cases demonstrate that globalization can be achieved via alternative paths and with results that are more balanced from the perspective of the periphery. It is also suggested that modern IT and information systems have no predestined 
character as the proponents of either globalization camp presume. IT and information systems can be and indeed have been used for creating various paths in globalization, as indicated in some of the cases discussed above. Interestingly, the world's developed core has also bent the neo-liberal formula in various ways. For example, in many developed countries the governments erected protectionist walls around agriculture by heavily subsidizing farmers. This practice is directly opposite to the prescript on free markets and deregulation. Also, without continuous and increasing public spending, the Internet would not be as available as it is in remote areas and economically disadvantaged communities within the core (Mignone \& Henley, 2009; Selouani \& Hamam, 2007).

Variation in globalization paths exposes limitations of the simplistic formula or model of globalizing via the free reign of markets, deregulation, and privatization. The formula is incapable of matching the complexity of the world system since it not only neglects specifics of particular countries but it directly favours the most powerful players. This is apparent in the role of supranational regulators of international economy - the World Bank and International Monetary Fund. Established after World War II to assist global economic recovery and cooperation, these organizations (later joined by World Trade Organization) evolved into instruments in hands of the strongest stakeholders - the G7 countries and special interest groups (Serra \& Stiglitz, 2008). The above cited Washington Consensus of 1989 signified the tipping point in this evolution. Developing countries and other weaker stakeholders in globalization have been hard pressed to pay back development loans and surrender planning of development, public spending (education, health care, and pensions) and government's intervention in economy to the impact of stronger stakeholders.

Today, both theoretical and practical reasons speak against the neo-liberal model of globalization. Approaching the world as a complex system presents another case in point (Gill, forthcoming). Complex systems exist on the boundary between order and chaos and exhibit behaviour of punctuated equilibrium (Bak, 1996). Complex systems can steadily evolve, resembling the state of equilibrium, and then suddenly change behaviour (punctuation - a discontinuity of the steady behaviour as when adding new grains of sand to a sand pile results in an avalanche). It is the timing of a punctuation that is unpredictable rather than the punctuation itself. Widespread downturns in capitalist economy (such as the global crisis of the credit system, which erupted in 2008) are an example of the punctuation or discontinuity in the world system. Gill (forthcoming) contends that globalization increases the size of complex systems and consequently the magnitude of discontinuities. IT also precipitates discontinuities since it increases the rate at which we can react to information. In effect, time is "compressed" and the frequency at which discontinuities happen is potentially increased. An implication of this punctuated equilibrium view for the globalizing world system appears warranted: the evolving world system is inherently prone to punctuations. As such, it requires constant care and creative intervention rather than prolonging of warn-out models that can only amplify chaos.

In summary, this last part of analysis has identified aspects of divergence in the transpired process of globalization. Social and historical circumstances make a difference across countries, thus refuting simplistic model of globalization based on unfettered reign of markets. The model fails to meet the law of requisite variety and may amplify chaos.

\section{Conclusion}

The discussion above illuminated some remarkable economic and associated political and cultural changes that have been studied under the rubric of globalization. The specific slant of the stakeholder analysis deployed was in focusing on TNC as the key organizational player. Analysis of TNC's organizational design, placed in the capability perspective, and of its information and IT foundations set the stage for discussing the role of TNC in the contemporary world system. Pow- 
ered by modern IT, digital information, and advanced knowledge, TNC possesses capabilities superior to local business organizations in terms of efficiency, learning, responsiveness, bargaining power, mobility, and global sourcing, producing, and selling. TNC also has capabilities of the virtual organization. Actions of TNC affect numerous stakeholders, often adversely, including the local business, labour, government, political parties, and population residing in the physical environment of TNC's operations, mass information media, and cultural institutions.

TNC has acted as the playmaker in the process of globalization that has delivered contrasting, or contradictory and paradoxical results. There has been an increase in wealth as well as in poverty; the inclusion in global knowledge and technology-based economy functioning around clock ("informational capitalism") along with exclusion of those unable to adjust technologically and organizationally; an advanced "techno-economy" based on fulfilling, specialist work along with a "grunge economy" based on deskilling, routine work; increasing employment in some regions along with increasing structural unemployment in other regions; benefits for TNCs and host countries at the macro level along with hardship for local business; formally more democratic political systems that should facilitate market economy along with uneven level playing field favouring special domestic and foreign interest; unprecedented technological capabilities for global spread of knowledge along with shrinking funds for education; greater opportunities for intercultural exchanges along with uneven information flows between the world's core and periphery; prosperity and freedoms along with misery and confusion. It was argued that the model behind this globalization is worn out.

A theoretical implication of the present study is in shedding the light on globalization from the perspective of information and IT that lie at the nexus of the key globalization player - TNC. This brings the important topic of globalization dynamics into research on information systems, which has been preoccupied with other cognate topics, such as IT transfer, e-commerce, cultural differences affecting information systems use, and offshore software production. In addition, the present study complements the multidisciplinary research on globalization with an information systems perspective. Moreover, the study continues organization theory on TNC founded by Bartlett and Ghoshal (1989). Finally, there is a contribution to informing science (Cohen, 1999, 2009; Gill, forthcoming; Gill \& Cohen, 2009). The argument presented here suggests that the informing model may be expanded by accounting for environmental consequences of informing processes as follows:

1. Although informing typically happens inside TNC (see Figure 3a), the affected side can ultimately include external actors - globalization stakeholder. This is so because informing precedes and shapes action, and actions of TNC affect companies, social groups, governments, and countries across the globe.

2. If TNC's business is to inform an external target client (Figure 3b), as is the case with the news, popular culture, education and research organizations, then the external client can also be subject to chance - remote random client. This is due to the far reaching, global presence of TNC.

From the informer perspective, these relationships between informing, on the one side, and globalization stakeholder and remote random client, on the other, may not be intended or apparent.

From the practical perspective, awareness of external consequences of informing can aid the informer in applying ethical criteria in evaluating informing engagements. In turn, such a step can help in selecting informing tasks or workplaces. This evaluation and selection becomes a factor in ultimate shaping of globalization processes. 


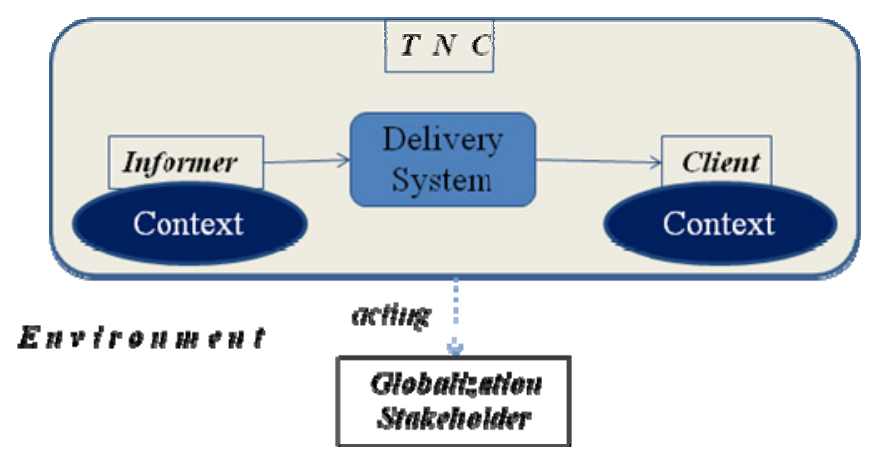

Figure 3a

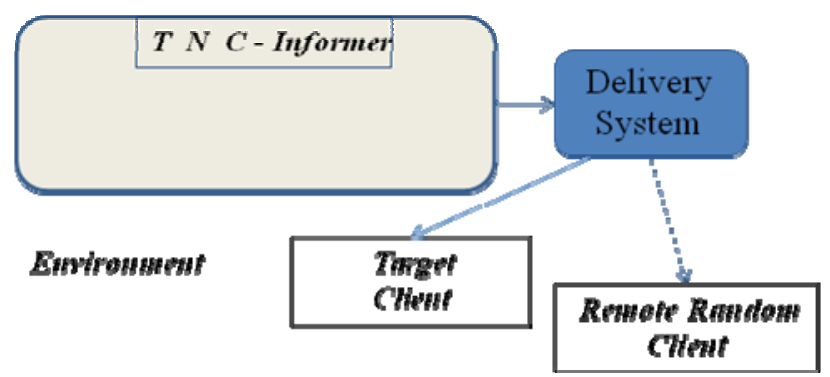

Figure 3b

\section{Figure 3. Informing Model with Environmental Extensions}

The present study was limited to TNC. Other drivers, such as supranational organizations were merely touched on in connection with TNC. Future research needs to concentrate on the relationship between TNC and other globalization-makers. A capability model of TNC proposed in this article is based on integrating the relevant literature. The model was used here as a device for exploring globalization that is conceived from a literature perspective. An extension of this research would be to test empirically the TNC model. Finally, future informing science research may want to take interest in TNC and investigate the proposed constructs of globalization stakeholder and remote random client in both theoretical and empirical fashion.

\section{References}

Ashby, W. R. (1958). Requisite variety and its implications for the control of complex systems. Cybernetica, $1(2)$.

Bak, P. (1996). How nature works: The science of self-organized criticality. New York: Copernicus.

Bartlett, C., \& Ghoshal, S. (1989). Managing across borders: The transnational solution. Boston, MA: Harvard Business School Press.

Castells, M. (1996). The rise of the network society. Oxford, UK: Blackwell.

Castells, M. (2000). Information technology and global capitalism. In W. Hutton, W. \& A. Giddens (Eds.), Global capitalism (pp. 52-74). New York: The New Press.

Chossudovsky, M. (2003). The globalization of poverty and the new world order. Shanty Bay, ON: Global Outlook.

Cohen, E. (1999). From ugly duckling to a swan: Reconceptualizing information systems as a field of the discipline informing science. Journal of Computing and Information Technology, 7(3), 213-219. 
Informing in the Flat, Rough World

Cohen, E. (2009). A philosophy of informing science. In T. G. Gill \& E. Cohen (Eds.), Foundations of informing science: 1999-2008 (pp. 767-788). Santa Rosa, CA: Informing Science Press.

Egelhoff, W. (2005). Information-processing theory and the multinational corporation. In S. Ghoshal \& E. Westney (Eds.), Organization theory and the multinational corporation (pp. 172-197). Houndmills, UK: Palgrave-Macmillan.

Freeman, R. (2007). The challenge of the growing globalization of labor markets to economic and social policy. In E. Paus (Ed.), Global capitalism unbound: Winner and losers from offshore outsourcing (pp. 23-40). New York, NY: Palgrave-Macmillan.

Friedman, T. (2007). The world is flat: A brief history of the twenty-first century. Vancouver: Douglas \& McIntyre.

Fukuyama, F. (1992). The end of history and the last man. Free Press.

Galbraith, J. (1973). Designing complex organizations. Reading, MA: Addison-Wesley.

Gill, T. G., \& Cohen, E. (Eds.). (2009). Foundations of informing science: 1999-2008. Santa Rosa, CA: Informing Science Press.

Gill, T. G. (Forthcoming). Informing business: Research and education on a rugged landscape. Santa Rosa, CA: Informing Science Press.

Handy, C. (1989). The age of unreason. Business Books.

Handy, C. (1995). The age of paradox. Harvard Business School Press.

Hiatt, S. (2007). Global empire: The web of control. In S. Hiatt (Ed.), A game as old as empire: The secret world of economic hit men and the web of global corruption (pp. 13-30). San Francisco, CA: BerrettKoehler.

Internet World Stats. (2009). Accessed October 5, 2009 from http://www.internetworldstats.com

Jones, M. T. (1998). Blade Runner capitalism, the transnational corporation, and commodification: Implications for cultural integrity. Cultural Dynamics, 10(3), 287-306

Jones, M. T. (2000). The competitive advantage of the transnational corporation as an institutional form. International Journal of Social Economics, 27, 943-958.

Jones, M. T. (2003). Globalization and the organization(s) of exclusion in advanced capitalism. In R. Westwood \& S. Clegg (Eds.), Debating organization: Point - counter point (pp. 252-270). Oxford, UK: Blackwell.

Jones, M. T., \& Fleming, P. (2003). Unpacking complexity through critical stakeholder analysis: The case of globalization. Business \& Society, 42(4), 430-454.

Kim, C., \& Mauborgne, R. (2005). Procedural justice and the multinational corporation. In S. Ghoshal \& E. Westney (Eds.), Organization theory and the multinational corporation (pp. 222-240). Houndmills, UK: Palgrave-Macmillan.

Klein, N. (2008). The shock doctrine: The rise of disaster capitalism. Toronto: Vintage Canada.

Kovacic, B., \& Travica, B. (1992). Yugoslavia: Ethnic dramas without denouement. In S. King \& D. Cushman (Eds.), Engineering visions of order in the socialist world. Albany, NY: State University of New York Press.

Lal, K. (2007). Information and communication technologies in the context of globalization. Houndmills, UK: Palgrave-Macmillan.

Levitt, T. (1983). The globalization of markets. In C. Bartlett \& S. Ghoshal (Eds.) (1995), Transnational management: Text, cases, and readings in cross-border management (pp. 183-193). Boston, MA: McGraw-Hill.

Leong, S. M., \& Tang, C. T. (1993). Managing across borders: An empirical assessment of the Bartlett and Ghoshal typology. Journal of International Business Studies, 24(3), 449-464. 
Mignone, J., \& Henley, H. (2009). Impact of information and communication technology on social capital in aboriginal communities in Canada. Journal of Information, Information Technology, and Organizations, 4, 127-145. Retrieved from http://jiito.org/articles/JIITOv4p127-145Mignone387.pdf

Mowshowitz, A. (1994). Virtual organization: A vision of management in the information age. The Information Society, 10(4), 267-288.

Nayyar, D. (2008). International migration and economic development. In N. Serra \& J. Stiglitz (Eds.). The Washington Consensus reconsidered: Toward a new global governance (pp. 277-308). Oxford, UK: Oxford University Press.

Palmisano, S. (2006). Beyond multinational. Foreign Affairs. May/June. Available at http://www.ibm.com/ibm/ideasfromibm/us/integration/june05/images/pdf/IFI_06052006.pdf

Paus, E. (2007). Winners and losers from offshore outsourcing: What is to be done? In E. Paus (Ed.), Global capitalism unbound: Winner and losers from offshore outsourcing (pp. 3-22). New York, NY: Palgrave-Macmillan.

Perkins, J. (2004.). Confessions of an economic hit man. San Francisco: Berret-Koehler.

Piatkowski, M. (2006). Can ICT make a difference in the development of transitions economies? In A. D'Costa (Ed.), The new economy in development: ICT challenges and opportunities (pp. 89-109). New York, NY: Palgrave-Macmillan.

Prebisch, R. (1950). The economic development of Latin America and its principal problems. New York: United Nations.

Roy, S. (2005). Globalisation, ICT and developing nations. New Delhi: Sage.

Sachs, J. D. (2005). The end of poverty: Economic possibilities for our time. New York: Penguin Press.

Selouani, S., \& Hamam, H. (2007). Social impact of broadband internet: A case study in the Shippagan Area, a rural zone in Atlantic Canada. Journal of Information, Information Technology, and Organizations, 2, 79-94. Retrieved from http://jiito.org/articles/JIITOv2p079-094Selouani74.pdf

Serra, N., \& Stiglitz, J. (Eds.), (2008). The Washington Consensus reconsidered: Toward a new global governance. Oxford, UK: Oxford University Press.

Simoneti, M., Böhm, A., Rems, M., Rojec, M., Damijan, J., \& Majcen, B. (2001). Secondary privatization in Slovenia: Evolution of ownership structure and company performance following mass privatization. Warsaw: Center for Social and Economic Research.

Stiglitz, J. (2003). Globalization and its discontents. New York: W.W. Norton.

Stiglitz, J. (2006). Making Globalization Work. New York: W.W. Norton.

Suri, N. (2007). Offshore outsourcing of services as a catalyst of economic development: The case of India. In E. Paus (Ed.), Global capitalism unbound: Winner and losers from offshore outsourcing (pp.163180). New York, NY: Palgrave-Macmillan.

Swivel Preview. (2009). Accessed November 12, 2009 from http://www.swivel.com/data_columns/show/2085645

Travica, B. (2002). Diffusion of electronic commerce in developing countries: The case of Costa Rica." Journal of Global Information Technology Management, 5(1), 4-24.

Travica, B. (2005a). Information view of organization. Journal of International Technology and Information Management, 14(3), 1-20.

Travica, B. (2005b). Virtual organization and electronic commerce. The DATA BASE for Advances in Information Systems, 36(3), 45-68.

Travica, B. (2008). The ISSAAC model of virtual organization. In G. Putnik \& M. M. Cunha (Eds.), Encyclopedia of networked and virtual organizations. Hershey, PA: IDEA. 
Informing in the Flat, Rough World

Wallerstein, R. (1974). The modern world system: Capitalist agriculture and the origins of the European world economy in the sixteenth century. New York: Academic Press.

Wikipedia. (2009). List of countries by GDP (nominal) per capita. Available:

http://en.wikipedia.org/wiki/List_of_countries_by_GDP_(nominal)_per_capita.

\section{Biography}

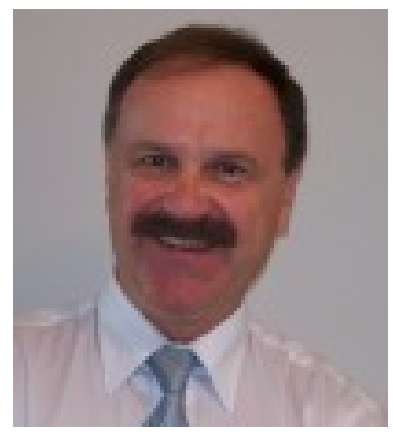

Bob Travica teaches information systems at University of Manitoba in Canada, and investigates organizations from the perspective of information and information technology management. His current preoccupations are with advancing an informing view of organization and with globalization aspects of information systems. 